\title{
Is high-frequency oscillatory ventilation more effective and safer than conventional protective ventilation in adult acute respiratory distress syndrome patients? A meta-analysis of randomized controlled trials
}

\author{
Xiao-ling Gu' , Guan-nan Wu'1, Yan-wen Yao' ${ }^{1}$ Dong-hong Shi² and Yong Song ${ }^{1 *}$
}

\begin{abstract}
Introduction: Comprehensively evaluating the efficacy and safety of high-frequency oscillatory ventilation (HFOV) is important to allow clinicians who are using or considering this intervention to make appropriate decisions.

Methods: To find randomized controlled trials (RCTs) comparing HFOV with conventional mechanical ventilation (CMV) as an initial treatment for adult ARDS patients, we searched electronic databases (including PubMed, MedLine, Springer Link, Elsevier Science Direct, ISI web of knowledge, and EMBASE) with the following terms: "acute respiratory distress syndrome", "acute lung injury", and "high frequency oscillation ventilation". Additional sources included reference lists from the identified primary studies and relevant meta-analyses. Two investigators independently screened articles and extracted data. Meta-analysis was conducted using random-effects models.

Results: We included 6 RCTs with a total of 1,608 patients in this meta-analysis. Compared with CMV, HFOV did not significantly reduce the mortality at 30 or 28 days. The pooled relative risk (RR) was 1.051 (95\% confidence interval (Cl) 0.813 to 1.358 ). ICU mortality was also not significantly reduced in HFOV group, with a pooled RR of 1.218 ( $95 \%$ Cl 0.925 to 1.604). The pooled effect sizes of HFOV for oxygenation failure, ventilation failure and duration of mechanical ventilation were 0.557 ( $95 \% \mathrm{Cl} 0.351$ to 0.884$), 0.892$ ( $95 \% \mathrm{Cl} 0.435$ to 1.829 ) and 0.079 ( $95 \% \mathrm{Cl}-0.045$ to 0.203 ), respectively. The risk of barotrauma and hypotension were similar between the CMV group and HFOV group, with a RR of 1.205 (95\% Cl 0.834 to 1.742 ) and a RR of 1.326 ( $95 \% \mathrm{Cl} 0.271$ to 6.476$)$, respectively.

Conclusions: Although HFOV seems not to increase the risk of barotrauma or hypotension, and reduces the risk of oxygenation failure, it does not improve survival in adult acute respiratory distress syndrome patients.
\end{abstract}

\section{Introduction}

Both acute lung injury (ALI) and acute respiratory distress syndrome (ARDS) are life-threatening conditions that are usually associated with substantial morbidity [1,2], mortality [3], and financial costs [4]. Conventional mechanical ventilation $(\mathrm{CMV})$ is still considered the cornerstone of treatment for these patients. However, although mechanical

\footnotetext{
*Correspondence: yong_song6310@yahoo.com

'Department of Respiratory Medicine, Jinling Hospital, Nanjing University School of Medicine, 305 East Zhongshan Road, Nanjing, Jiangsu Province 210002, P. R. China

Full list of author information is available at the end of the article
}

ventilation can initially sustain life, it may cause further lung injury [5-8].

To avoid ventilator-induced lung injury, lung-protective ventilation has been recommended, which focused on avoiding cyclic alveolar collapse and re-expansion, preventing alveolar excess distension, and achieving and maintaining alveolar recruitment [9-11]. High-frequency oscillation is an alternative mechanical ventilation method that delivers very small tidal volumes at high frequencies (3 to $15 \mathrm{~Hz}$ ) using an oscillatory pump [12]. Highfrequency oscillatory ventilation (HFOV) can not only avoid over-distension of alveoli by delivering small tidal

\section{Ciomed Central}

(c) 2014 Gu et al.; licensee BioMed Central Ltd. This is an Open Access article distributed under the terms of the Creative Commons Attribution License (http://creativecommons.org/licenses/by/4.0), which permits unrestricted use, distribution, and reproduction in any medium, provided the original work is properly credited. The Creative Commons Public Domain Dedication waiver (http://creativecommons.org/publicdomain/zero/1.0/) applies to the data made available in this article, unless otherwise stated. 
volumes but can also prevent end-expiratory alveolar collapse and maintain alveolar recruitment by applying a constant airway pressure [13-15]. Therefore, HFOV theoretically achieves all goals pursued by lung-protective ventilation strategies $[11,16,17]$.

However, no more than six randomized controlled trials (RCTs) in adult ARDS patients have been published on the safety and efficacy of HFOV as an initial treatment strategy. Three previous trials comparing HFOV with CMV suggested that HFOV improved both oxygenation and survival in adults with ARDS [18-20], but two recent larger-scale RCTs presented different or even opposite results $[21,22]$. Therefore, this approach remains an unproven and controversial therapy for adults with ARDS [23-26].

Two Cochrane reviews examining the effect of HFOV on mortality in ALI/ARDS patients have been published. The earlier one found only two small RCTs and was not powerful enough to draw definitive conclusions [27]; the later study [28] concluded that HFOV might improve survival, which was not completely consistent with the conclusions of two recently published large RCTs [21,22]. Neither of the above two Cochrane reviews focused on the effect of HFOV in unique adults with ARDS. Since two large scale RCTs comparing HFOV with CMV as an initial treatment for unique adult ARDS patients have been recently published, we performed a meta-analysis of RCTs, to systematically review the efficacy and safety of HFOV in the population of adult ARDS patient compared with CMV.

\section{Methods and materials}

\section{Ethics statement}

We performed a meta-analysis of published RCTs comparing HFOV with CMV for ALI/ARDS in unique adult patients. All analyses were based on published data extracted from the six eligible studies, which have been approved by the Institutional Review Committee on Human Research. An additional file shows this in more detail (see Additional file 1). Additionally, as described in the six primary studies, all patients (or their representatives) enrolled in these six trials have provided written informed consent before any study-related procedure was performed. Therefore, the present meta-analysis does not present any further problems in relation to ethics or conflicts of interest.

\section{Literature search and identification of the publications}

To identify all published RCTs comparing HFOV with CMV in adult ARDS patients, a search of electronic databases (including PubMed, MedLine, Springer Link, Elsevier Science Direct, ISI web of knowledge, and EMBASE) was carried out with the following terms: acute respiratory distress syndrome; acute lung injury; high frequency oscillation ventilation. There were no language restrictions. This search was conducted through July 2013, with no additional time limits. The reference lists of the identified primary studies and relevant metaanalyses were also searched for additional studies.

To be included in the present meta-analysis, studies had to be RCTs comparing HFOV with CMV, enrolling unique adult ALI/ARDS patients, and reporting at least one of the following outcomes of interest: ICU mortality; 28- or 30-day mortality; hypoxemia and ventilation failure; duration of mechanical ventilation; and the incidence of barotrauma or hypotension. All of the candidate articles were independently read and checked for the inclusion criteria by two investigators (XG and GW). Disagreements were resolved through consensus. The methodological quality of the included studies was evaluated according to the Cochrane handbook 5.1.0 for randomized controlled trials [29]. Given that blinding of physicians, patients or related family members was impossible in those trials, we compared whether rescue treatments were equally applied in the treatment group and control group, and performed quality assessment according to the following five aspects, including random sequence generation, allocation concealment, incomplete outcome data, selective reporting, and others.

\section{Data extraction}

Information was extracted independently by two investigators (XG and $\mathrm{GW})$ from all eligible studies. The required items included in the data form were as follows: (1) basic information about the primary study, including the first author's name, year of publication, sample size of the study, single or multicenter design, the definition of ALI or ARDS used, and the overall risk of bias; (2) clinically relevant primary outcomes, including ICU mortality, 28- or 30-day mortality, hypoxemia (including oxygenation failure and refractory hypoxemia diagnosed in the primary eligible studies) and ventilation failure (including ventilation failure, acidosis, and refractory acidosis diagnosed in the primary eligible studies), and duration of mechanical ventilation; and (3) the incidence of barotrauma or hypotension. The lists from the two investigators were compared, and disagreements about the extracted data were resolved by consensus.

\section{Statistical analyses}

All meta-analysis were performed by random-effects models (the DerSimoniane and Laird method). We reported continuous outcomes using standardized mean differences with the $95 \% \mathrm{CI}$, and binary outcomes were presented as relative risk with the $95 \% \mathrm{CI}$. The $Z$-test and chi-square test were used to generate the $P$-value for the continuous outcomes and for the binary outcomes, respectively. $P<0.05$ was considered statistically significant. 
The presence of heterogeneity between studies was tested with the chi-square-based Q-test and quantified with the $I^{2}$ statistic (25 to $49 \%$ for low heterogeneity, 50 to $74 \%$ for moderate heterogeneity, and 75 to $100 \%$ for high heterogeneity) [30]. Sensitivity analysis was performed to evaluate the influence of the individual trial on the pooled effect. Potential publication bias was investigated by funnel plots and was formally evaluated with Egger's linear regression test and Begg's adjusted rank correlation test. All statistical analyses were performed with Stata software (version 11.0; StataCorp LP, College Station, TX, USA) using two-sided $\mathrm{p}$ values. $P<0.05$ was considered statistically significant.

\section{Results}

\section{Literature search and study characteristics}

Using the search term high frequency oscillatory ventilation combined with acute respiratory distress syndrome or with acute lung injury, 784 citations were identified. Among them, six trials [18-22,31] met the inclusion criteria and were enrolled in the meta-analysis. The flow chart of the identification and selection of publications is shown in Figure 1.

Six eligible trials [18-22,31] enrolled a total of 1,608 adult patients with ARDS (Table 1). All trials investigated HFOV as an initial treatment for ARDS rather than as a rescue treatment after the failure of conventional ventilation. The tested patients in most of these trials were continuously treated with HFOV for more than 24 hours, except in one trial that continuously applied highfrequency oscillation for 12 hours [20]. The control groups in four trials underwent low-tidal-volume ventilation $(\leq 8 \mathrm{ml} / \mathrm{kg})[20-22,31]$, whereas three trials performed low plateau pressure $\left(\leq 35 \mathrm{~cm} \mathrm{H}_{2} \mathrm{O}\right)[20,21,31]$. Among all of the included studies, five studies with high methodological quality and low risk of bias passed the quality assessment [18,20-22,31], and the risk of bias in the sixth trial was unclear [19] (Table 1).

\section{Mortality at $\mathbf{2 8}$ or $\mathbf{3 0}$ days}

In the primary analysis of five trials $[18,19,21,22,31]$ $(n=1,580)$, the median mortality at 30 or 28 days in the control group and the HFOV group was $41.1 \%$ (range 28.6 to $52.1 \%$ ) and $40.4 \%$ (range 37.3 to $43.2 \%$ ), respectively. The results of the meta-analysis suggested that HFOV did not significantly reduce mortality at 30 or 28 days in adult ARDS patients (relative risk (RR) 1.051, 95\% CI 0.813, 1.358; Table 2 and Figure 2A). As significant heterogeneity was detected among the above five enrolled studies $\left(I^{2}=63.1 \%, P=0.028\right)$, and considering the tidal volume and plateau airway pressure might be the sources of heterogeneity, we performed subgroup analysis stratified by the tidal volume ( $\leq 8 \mathrm{ml} / \mathrm{kg}$ predicted body weight) and by the plateau airway pressure $(\leq 35 \mathrm{cmH} 2 \mathrm{O})$ in the control group, respectively. The results of these subgroup analyses also suggest that HFOV failed to reduce mortality at 30 or 28 days in adult ARDS patients. These results of subgroup analysis and the related forest plot are shown in Table 2 and Figure 2A, B.

Sensitivity analysis was also analyzed, and the results demonstrated that after each study was excluded from the overall meta-analysis, similar results were obtained

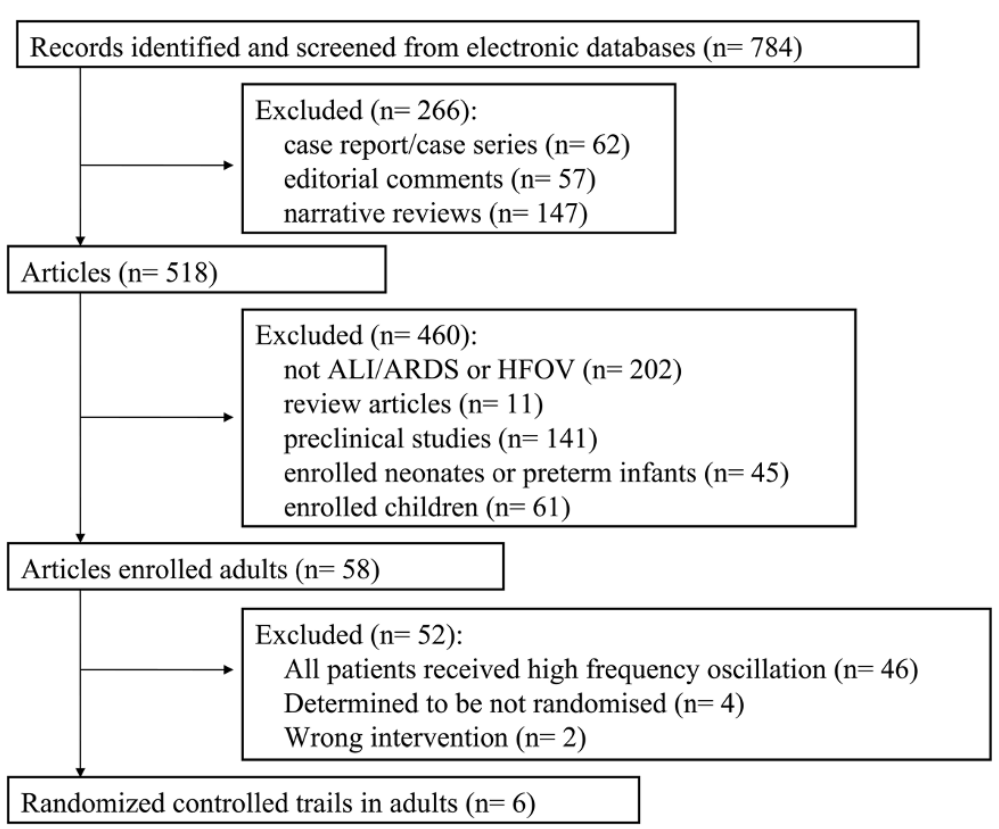

Figure 1 Flow chart of studies included in this meta-analysis. 
Table 1 Essential characteristics of included studies

\begin{tabular}{|c|c|c|c|c|c|c|}
\hline \multirow[t]{2}{*}{ First author } & \multirow[t]{2}{*}{ Year } & \multirow[t]{2}{*}{ Institute } & \multicolumn{2}{|c|}{ Patients (number) } & \multirow[t]{2}{*}{ Details of ARDS } & \multirow[t]{2}{*}{ Overall risk of bias } \\
\hline & & & HFOV & CMV & & \\
\hline Derdak [18] & 2002 & ICUs in 13 US hospitals & 75 & 73 & ARDS; PEEP $<10 \mathrm{~cm} \mathrm{H}_{2} \mathrm{O}$ & Low \\
\hline Shah [31] & 2004 & $1 \mathrm{ICU}$ in Cardiff, Wales & 15 & 13 & ARDS & Low \\
\hline Bollen [19] & 2005 & 5 ICUs in 4 European cities & 37 & 24 & ARDS & Unclear (>10\% (11/61) crossovers, \\
\hline Demory [20] & 2007 & 1 ICU in Marseille, France & 13 & 15 & ARDS; $\mathrm{PaO}_{2} / \mathrm{FiO}_{2} \leq 150, \mathrm{PEEP} \geq 5 \mathrm{cmH} 2 \mathrm{O}$ & Low \\
\hline Young [22] & 2013 & $\begin{array}{l}\text { ICUs in England, Wales, } \\
\text { and Scotland }\end{array}$ & 398 & 397 & ARDS; $\mathrm{PaO}_{2} / \mathrm{FiO}_{2} \leq 200, \mathrm{PEEP} \geq 5 \mathrm{cmH} 2 \mathrm{O}$ & Low \\
\hline Ferguson [21] & 2013 & $\begin{array}{l}38 \text { centers in Canada, the } \\
\text { United States, Saudi Arabia, } \\
\text { Chile, and India }\end{array}$ & 275 & 273 & ARDS; $\mathrm{PaO}_{2} / \mathrm{FiO}_{2} \leq 200, \mathrm{FiO}_{2} \geq 0.5$ & Low \\
\hline
\end{tabular}

ARDS, acute respiratory distress syndrome; $\mathrm{CMV}$, conventional mechanical ventilation; $\mathrm{FiO}_{2}$, fraction of inspired oxygen; HFOV, high-frequency oscillatory ventilation; $\mathrm{PaO}_{2}$, arterial oxygen tension; PEEP, positive end expiratory pressure.

(Table 3). No publication bias of the enrolled studies was observed (Table 4).

\section{ICU mortality}

Three eligible studies [20-22] $(n=1,371)$ reported ICU mortality. The median mortality in the control group and the HFOV group was $30.8 \%$ (range 26.7 to $42.1 \%$ ) and $44.2 \%$ (range 30.8 to $44.7 \%$ ), respectively. We performed a meta-analysis using a random-effects model, and the results of this meta-analysis suggested that high-frequency oscillatory ventilation did not significantly reduce or increase the risk of death in ICU compared with conventional mechanical ventilation in adult ARDS patients
(RR 1.218, 95\% CI 0.925, 1.604; Table 2 and Figure 2C). However, the sensitivity analysis showed that a paradoxical result obtained after the OSCAR trial [22] was excluded from the overall meta-analysis, and it suggested that HFOV would significantly increase the ICU mortality in adult ARDS patients (RR 1.442, 95\% CI 1.160, 1.792; Table 3). Neither Egger's test nor Begg's test showed any evidence of publication bias (Table 4).

\section{Oxygenation failure, ventilation failure and duration of mechanical ventilation}

Oxygenation failure was defined as persisting abnormal low oxygenation index or refractory hypoxemia after the

Table 2 Main results of meta-analysis of mortality

\begin{tabular}{|c|c|c|c|c|c|c|c|}
\hline & \multirow{2}{*}{$\begin{array}{l}\text { Studies } \\
\text { included (n) }\end{array}$} & \multicolumn{2}{|c|}{ Case number (n) } & \multicolumn{2}{|c|}{ Heterogeneity } & \multirow{2}{*}{$\begin{array}{l}\text { Pooled RR } \\
(95 \% \mathrm{CI})\end{array}$} & \multirow[t]{2}{*}{$P$} \\
\hline & & HFOV & CMV & $I^{2}(\%)$ & $P$ & & \\
\hline \multirow[t]{2}{*}{ Mortality at $\mathbf{2 8}$ or $\mathbf{3 0}$ days } & 5 & 800 & 780 & 63.1 & 0.028 & 1.051 & 0.704 \\
\hline & & & & & & $(0.813,1.358)$ & \\
\hline \multicolumn{8}{|l|}{ Subgroup } \\
\hline \multicolumn{8}{|l|}{$\begin{array}{l}\text { Tidal volume in control } \\
\text { group }<8 \mathrm{ml} / \mathrm{kg}\end{array}$} \\
\hline \multirow[t]{2}{*}{ Mandated } & 3 & 688 & 683 & 63.1 & 0.067 & 1.149 & 0.329 \\
\hline & & & & & & $(0.869,1.519)$ & \\
\hline \multirow[t]{2}{*}{ Not mandated } & 2 & 112 & 97 & 56.4 & 0.13 & 0.899 & 0.712 \\
\hline & & & & & & $(0.511,1.582)$ & \\
\hline \multicolumn{8}{|l|}{$\begin{array}{l}\text { Plateau pressure in control } \\
\text { group }<35 \mathrm{cmH}_{2} \mathrm{O}\end{array}$} \\
\hline \multirow[t]{2}{*}{ Mandated } & 2 & 290 & 286 & 14.6 & 0.279 & 1.323 & 0.092 \\
\hline & & & & & & $(0.955,1.834)$ & \\
\hline \multirow[t]{2}{*}{ Not mandated } & 3 & 510 & 494 & 44.7 & 0.164 & 0.942 & 0.665 \\
\hline & & & & & & $(0.720,-1.233)$ & \\
\hline \multirow[t]{2}{*}{ ICU mortality } & 3 & 686 & 685 & 63.3 & 0.066 & 1.218 & 0.160 \\
\hline & & & & & & $(0.925,1.604)$ & \\
\hline
\end{tabular}




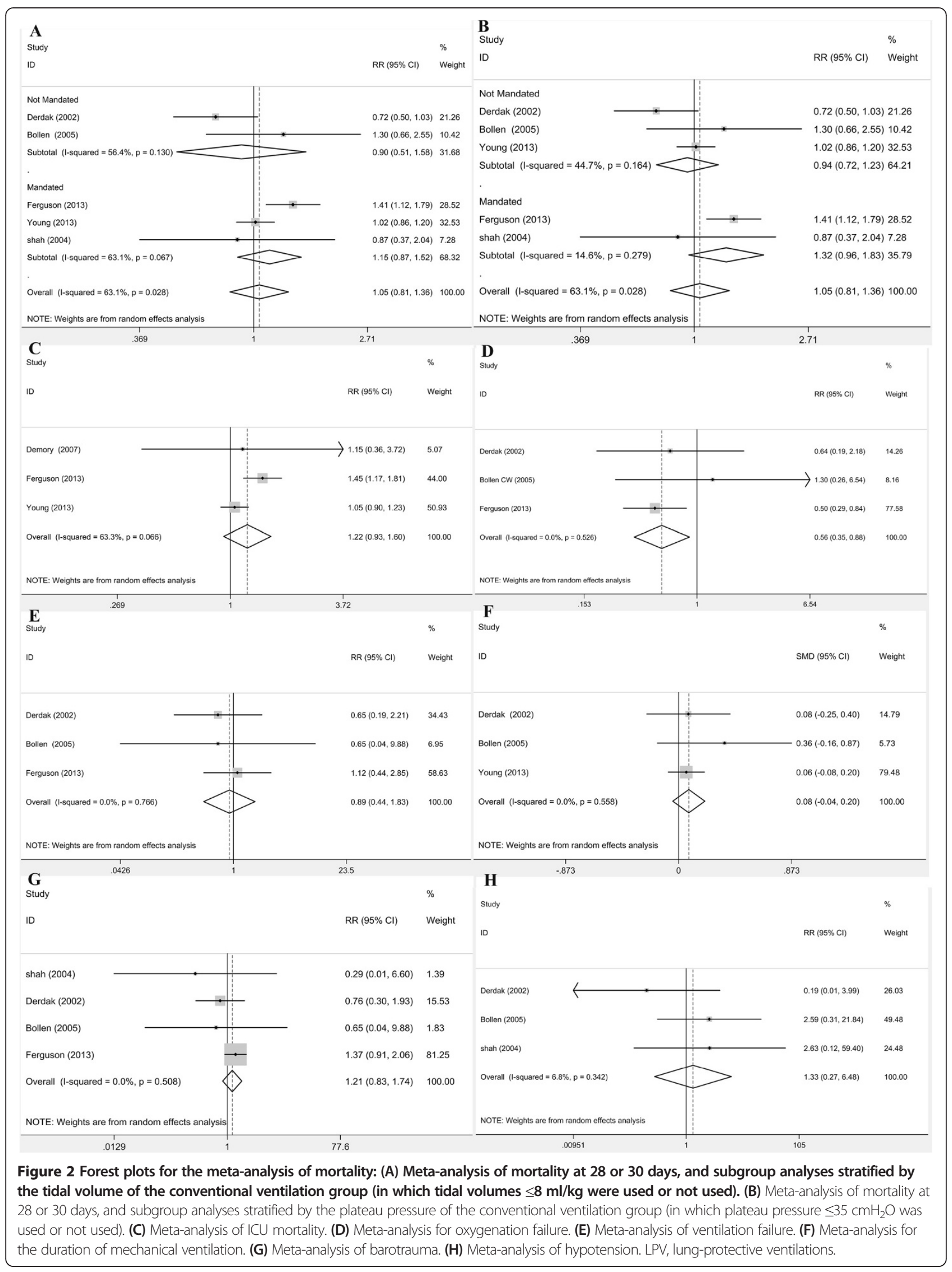


Table 3 Sensitivity analysis

\begin{tabular}{|c|c|c|}
\hline Excluded study & Relative risk & $95 \% \mathrm{Cl}$ \\
\hline \multicolumn{3}{|c|}{ Mortality at 28 or 30 days } \\
\hline Derdak (2002) & 1.164289 & $0.9238705,1.4672717$ \\
\hline Bollen (2005) & 1.0212231 & $0.76526242,1.3627961$ \\
\hline Ferguson (2013) & 0.94643247 & $0.77333957,1.158268$ \\
\hline Young (2013) & 1.0512564 & $0.69253296,1.5957943$ \\
\hline Shah (2004) & 1.0661671 & $0.80484247,1.4123416$ \\
\hline \multicolumn{3}{|l|}{ ICU mortality } \\
\hline Demory (2007) & 1.2246462 & $0.89132315,1.6826202$ \\
\hline Ferguson (2013) & 1.0530359 & $0.89893317,1.2335562$ \\
\hline Young (2013) & 1.4420993 & $1.160399,1.7921858$ \\
\hline \multicolumn{3}{|c|}{ Oxygenation failure } \\
\hline Derdak (2002) & 0.58428353 & $0.28815368,1.1847403$ \\
\hline Bollen (2005) & 0.51638663 & $0.31883517,0.83634168$ \\
\hline Ferguson (2013) & 0.82795441 & $0.31200156,2.1971316$ \\
\hline \multicolumn{3}{|c|}{ Ventilation failure } \\
\hline Derdak (2002) & 1.0543551 & $0.4344992,2.5584965$ \\
\hline Bollen (2005) & 0.91356009 & $0.43406373,1.9227407$ \\
\hline Ferguson (2013) & 0.64884853 & $0.2125513,1.9807193$ \\
\hline \multicolumn{3}{|c|}{ Duration of mechanical ventilation } \\
\hline Derdak (2002) & 0.09791627 & $-0.09584169,0.29167423$ \\
\hline Bollen (2005) & 0.06240474 & $-0.06527908,0.19008856$ \\
\hline Young (2013) & 0.15380768 & $-0.11983663,0.427452$ \\
\hline \multicolumn{3}{|l|}{ Barotrauma } \\
\hline Shah (2004) & 1.229754 & $0.84895152,1.7813679$ \\
\hline Derdak (2002) & 1.3130077 & $0.87979519,1.9595348$ \\
\hline Bollen (2005) & 1.1886587 & $0.78003234,1.8113472$ \\
\hline Ferguson (2013) & 0.6947636 & $0.29700547,1.6252108$ \\
\hline \multicolumn{3}{|l|}{ Hypotension } \\
\hline Derdak (2002) & 2.6042271 & $0.44842839,15.123928$ \\
\hline Bollen (2005) & 0.69353223 & $0.05379397,8.9412804$ \\
\hline Shah (2004) & 0.89276189 & $0.0725222,10.990066$ \\
\hline
\end{tabular}

treatment of mechanical ventilation. The meta-analysis of three eligible studies $[18,19,21](n=757)$ that reported the incidence of oxygenation failure demonstrated HFOV significantly reduced the risk of oxygenation failure compared with conventional ventilation (RR $0.557,95 \%$ CI $0.351,0.884$; Figure 2D). The result of sensitivity analysis showed HFOV would not significantly improve oxygenation compared with CMV, when the study of Derdak [18] or the OSCILLATE trial [21] was excluded from the overall meta-analysis (Table 3). It suggested that the result of this meta-analysis for oxygenation failure was not stable, and that further clinical trials are needed to determine whether HFOV is more effective than CMV for the improvement of oxygenation in adult ARDS patients. No publication bias of the enrolled studies was observed (Table 4).

Three enrolled studies demonstrated the ventilation efficiency of HFOV: one study [21] reported the incidence of refractory acidosis, one [19] reported the occurrence of acidosis, and the third [18] reported the incidence of ventilation failure with a clear definition, that is, 'a $\mathrm{pH} \leq 7.15$ for 6 hours and a bicarbonate of $19 \mathrm{meq} / \mathrm{L}$ or more'. We performed a meta-analysis with a random-effects model and demonstrated that there was no significant difference in ventilation efficiency between the HFOV group and the control group (RR 0.892, 95\% CI 0.435, 1.829; Figure 2E). Sensitivity analysis demonstrated that after each study was excluded from the overall meta-analysis, similar results were obtained (Table 3). No publication bias of the enrolled studies was observed (Table 4).

Three eligible trials $[18,19,22](n=1,004)$ provided the duration of mechanical ventilation. The results of metaanalysis showed that the high-frequency oscillation strategy did not significantly reduce the duration of mechanical ventilation (standardized mean difference $0.079,95 \%$ CI $-0.045,0.203$; Figure 2 F). Sensitivity analysis demonstrated that after each study was excluded from the overall meta-analysis, similar results were obtained (Table 3). No publication bias of the enrolled studies was observed (Table 4).

Table 4 Publication bias

\begin{tabular}{lllll}
\hline Type of meta-analysis & Begg's test & & Egger's test & $\boldsymbol{t}$ \\
\cline { 2 - 5 } & $\mathbf{z}$ & $\mathbf{P r}>|\mathbf{z}|$ & -0.230 & 0.833 \\
\hline Mortality at 28 or 30 days & 0.000 & 1.000 & 0.250 & 0.841 \\
ICU mortality & 0.520 & 0.602 & 2.39 & 0.252 \\
Oxygenation failure & 1.57 & 0.117 & -0.73 & 0.597 \\
Ventilation failure & -0.52 & 0.602 & 1.49 & 0.376 \\
Duration of mechanical ventilation & 1.04 & 0.296 & -2.67 & 0.116 \\
Barotrauma & -0.68 & 0.497 & -0.62 & 0.646 \\
Hypotension & -0.52 & 0.602 & & \\
\hline
\end{tabular}




\section{Adverse event: barotrauma}

Barotrauma was defined as a group of symptoms caused by the high airway pressure during mechanical ventilation, such as pneumothorax, pneumomediastinum, pneumopericardium, subcutaneous emphysema and so on. We performed a meta-analysis to summarize the difference in the risk of barotrauma between the HFOV group and control group. Four enrolled studies provided the incidence of barotrauma, but they all applied different definitions of barotrauma: only pneumothorax [31], any pulmonary air leak [18], severe air leak resulting in treatment failure [19], or new-onset barotrauma [21]. The above four enrolled trails reported the incidence of barotrauma in the HFOV group as 0/15 [31], 7/75 [18], $1 / 37$ [19], 46/256 [21] patients, respectively; and in the CMV group as 1/13 [31], 9/73 [18], 1/24 [19], 34/259 [21] patients, respectively. The results of the metaanalysis and the forest plot are shown in Figure 2G. The relative risk for barotrauma was 1.205 (95\% CI 0.834 , 1.742). This result suggests that HFOV does not increase or reduce the risk of barotrauma compared with CMV. In the sensitivity analysis, similar results were obtained after each study was excluded from the overall metaanalysis (Table 3). No publication bias of the enrolled studies was observed (Table 4).

\section{Adverse event: hypotension}

Three eligible trials $(n=237)$ reported the incidence of hypotension in the HFOV group as 0/75 [18], 4/37 [19], $1 / 15$ [31] patients, respectively; and in the CMV group as $2 / 73$ [18], 1/24 [19], 0/13 [31] patients, respectively. The results of meta-analysis demonstrated that the HFOV would not significantly increase the risk of hypotension compared with CMV (RR 1.326, 95\% CI 0.271, 6.476; Figure $2 \mathrm{H})$. Sensitivity analysis demonstrated that after each study was excluded from the overall meta-analysis, similar results were obtained (Table 3 ). No publication bias of the enrolled studies was observed (Table 4).

\section{Discussion}

To the best of our knowledge, the present study is the first meta-analysis examining the effect of HFOV in unique adults with ARDS, although two cognate Cochrane reviews $[27,32]$ have been published based on studies including mutually exclusive groups of patients, and the more recent one [32] combined the results from adult and pediatric patients. Importantly, the efficacy of HFOV is likely associated with the age of the patient, as Arnold et al. reported that patients older than five years had dramatically increased mortality compared with patients younger than five years, when treated with HFOV [33]. Additionally, the earlier Cochrane review [27] found only two small RCTs and was not powerful enough to draw definitive conclusions. Although the later one [32] included eight randomized controlled trials with 419 patients, it included two studies investigating the combination effect of HFOV and additional interventions (prone positioning [34] and tracheal gas insufflation [35]), which would complicate the results of meta-analysis.

In the present meta-analysis of mortality, we showed that HFOV did not significantly reduce mortality at 30 or 28 days compared with CMV. This finding contrasts sharply with experimental studies in animals in which benefits of high-frequency oscillation were observed [36]. Our results may suggest that the benefits of HFOV cannot be translated directly from animal models to adult ARDS patients, probably because there is great heterogeneity in the recruitability of the lung [37] and because the well-controlled conditions of animal studies are often difficult to replicate in human clinical trials. Our results are also at variance with those of the latest Cochrane review of HFOV in 2013 [32], which showed HFOV significantly reduced in-hospital or 30-day mortality compared with conventional ventilation. This may be simply because the present meta-analysis enrolled two more large multicenter trials and recruited more than three times the number of patients recruited in the previous meta-analysis. Our results are consistent with those of two recently published large-scale RCTs, which are known as the OSCILLATE trial [21] and OSCAR trial [22], respectively. Sensitivity analysis showed that in the meta-analysis of mortality at 30 or 28 days, after each study was excluded from the overall meta-analysis, similar results were obtained. This suggests that our results of 30- or 28-day mortality are valid.

As moderate heterogeneity was revealed in the overall meta-analysis of mortality, and considering that the tidal volume and plateau airway pressure might be the sources of heterogeneity, we performed subgroup analysis according to the tidal volume $(\leq 8 \mathrm{ml} / \mathrm{kg}$ predicted body weight) and according to the plateau airway pressure $(\leq 35 \mathrm{cmH} 2 \mathrm{O}$ ) in the control group, respectively. Although the heterogeneity remained moderate after the stratification by tidal volume, the heterogeneity was significantly reduced when the data were stratified depending on the control group's plateau airway pressure. It appears that the plateau airway pressure is one of the most possible sources of heterogeneity. The results from these subgroup analyses all suggest that HFOV did not significantly reduce mortality at 30 or 28 days in adult ARDS patients. This indicates that the results of this meta-analysis are stable.

Although the meta-analysis of ICU mortality demonstrated that HFOV did not significantly affect ICU mortality compared with CMV, the sensitivity analysis showed that the OSCAR trial [22] drastically affected the pooled results of our meta-analysis of ICU mortality. After the OSCAR trial was excluded, the pooled results suggested that the application of HFOV would significantly increase 
ICU mortality compared with CMV. Additionally, the beneficial effect of HFOV on mortality could have been underestimated because one study [21] enrolled $40 \%$ of the patients included in our meta-analysis of ICU mortality, and in that study more than $10 \%$ of patients in the control group crossed over to receive HFOV. Thus, the result of this meta-analysis of the risk of death in ICU was not stable, and further clinical trials are needed to determine whether HFOV is as effective as CMV for the improvement of ICU survival in adult ARDS patients.

The present meta-analysis showed that HFOV significantly reduced the risk of hypoxemia compared with CMV. This result is consistent with our meta-analysis of the $\mathrm{PaO}_{2} / \mathrm{FiO}_{2}$ ratio on day 1 which demonstrated that the application of HFOV significantly improved the $\mathrm{PaO}_{2} / \mathrm{FiO}_{2}$ ratio on the first day after the initiation of mechanical ventilation (data not shown). However, the sensitivity analysis showed whenever the OSCILLATE trial [21] or the study by Derdak et al. [18] was excluded, the pooled results of the other two studies suggested that HFOV did not significantly reduce the incidence of oxygenation failure. This may be simply because the other two trials enrolled too few patients to identify a significant difference. Thus, it is still possible that the application of HFOV significantly improves oxygenation and reduces the risk of hypoxemia.

There are several limitations of the present metaanalysis. First, the six enrolled studies were published between 2002 and 2013, which may have caused moderate heterogeneity of the control group and therefore complicated the results of this meta-analysis. Second, the sample size of the included trials ranged from 28 to 795 , which could have influenced the precision of the pooled effect-estimates. Lastly, we only evaluated the effect of HFOV on the incidence of barotrauma and hypotension, therefore, the evaluation of the safety of HFOV might not be comprehensive enough.

\section{Conclusions}

The pooled analysis of the currently available data suggests that HFOV does not significantly reduce mortality at 30 or 28 days, nor does it reduce ICU mortality, although it seems to significantly reduce the risk of oxygenation failure in adult ARDS patients. Furthermore, HFOV has no significant effect on the incidence of ventilation failure, the duration of mechanical ventilation or the risk of barotrauma and hypotension. Although these results suggest HFOV would not increase the incidence of barotrauma or hypotension, they do not support the recommendation that HFOV is used in routine care for adult patients with ARDS. More large-scale multicenter RCTs are required to further determine the efficacy and safety of HFOV in adult ARDS patients.

\section{Key messages}

- In adult ARDS patients, high-frequency oscillation did not significantly reduce mortality at 30 or 28 days, or the mortality within the ICU compared with CMV.

- Compared with conventional ventilation, HFOV, although having no significant effect on the incidence of ventilation failure or the duration of mechanical ventilation, significantly reduced the risk of oxygenation failure.

- High-frequency oscillatory ventilation was not associated with an increased risk of barotrauma or hypotension and seemed to be as safe as conventional ventilation.

\section{Additional file}

Additional file 1: The names of all ethical bodies involved in the six enrolled trials. All ethical body names involved in the six trials that were enrolled in the present meta-analysis have been listed in this file.

\section{Abbreviations}

ALI: acute lung injury; ARDS: acute respiratory distress syndrome; CMV: conventional mechanical ventilation; $\mathrm{FiO}_{2}$ : fraction of inspired oxygen; HFOV: high-frequency oscillatory ventilation; $\mathrm{PaO}_{2}$ : arterial oxygen tension; PEEP: positive end expiratory pressure; RCT: randomized controlled trial;

RR: relative risk; SMD: standardized mean difference.

\section{Competing interests}

The authors declare that they have no competing interests.

\section{Authors' contributions}

All authors conceived the study and contributed to the study design. XLG and GNW performed the literature review and data extraction. YWY and DHS performed statistical analysis. GNW, DHS and YS analyzed and interpreted the data. XLG, DHS and YWY drafted the manuscript. XLG, GNW and YS were responsible for the revision of the manuscript for important intellectual content. YS supervised the study. All authors have read and approved the manuscript for submission.

\section{Acknowledgements}

The present study was supported by the National Natural Scientific Foundation of China (numbers 81170064 and 81370172). The National Natural Scientific Foundation of China Grants did not directly participate in the literature search, determination of study eligibility criteria, data analysis or interpretation, or preparation, review, or approval of the manuscript for publication. Statements in the manuscript should not be construed as an endorsement by the National Natural Scientific Foundation of China.

\section{Author details}

${ }^{1}$ Department of Respiratory Medicine, Jinling Hospital, Nanjing University School of Medicine, 305 East Zhongshan Road, Nanjing, Jiangsu Province 210002, P. R. China. 'Department of Medical Imaging, Jinling Hospital, Nanjing University School of Medicine, 305 East Zhongshan Road, Nanjing, Jiangsu Province 210002, P. R. China.

Received: 27 September 2013 Accepted: 6 May 2014 Published: 30 May 2014

\section{References}

1. Herridge MS, Cheung AM, Tansey CM, Matte-Martyn A, Diaz-Granados N, Al-Saidi F, Cooper AB, Guest CB, Mazer CD, Mehta S, Stewart TE, Barr A, Cook D, Slutsky AS, Canadian Critical Care Trials Group: One-year outcomes in survivors of the acute respiratory distress syndrome. N Engl J Med 2003, 348:683-693. 
2. Angus DC, Musthafa AA, Clermont G, Griffin MF, Linde-Zwirble WT, Dremsizov TT, Pinsky MR: Quality-adjusted survival in the first year after the acute respiratory distress syndrome. Am J Respir Crit Care Med 2001, 163:1389-1394.

3. Villar J, Kacmarek RM, Perez-Mendez L, Aguirre-Jaime A: A high positive end-expiratory pressure, low tidal volume ventilatory strategy improves outcome in persistent acute respiratory distress syndrome: a randomized, controlled trial. Crit Care Med 2006, 34:1311-1318.

4. Cheung AM, Tansey CM, Tomlinson G, Diaz-Granados N, Matte A, Barr A Mehta S, Mazer CD, Guest CB, Stewart TE, Al-Saidi F, Cooper AB, Cook D, Slutsky AS, Herridge MS: Two-year outcomes, health care use, and costs of survivors of acute respiratory distress syndrome. Am J Respir Crit Care Med 2006, 174:538-544.

5. Ranieri VM, Suter PM, Tortorella C, De Tullio R, Dayer JM, Brienza A, Bruno F, Slutsky AS: Effect of mechanical ventilation on inflammatory mediators in patients with acute respiratory distress syndrome: a randomized controlled trial. JAMA 1999, 282:54-61.

6. Chiumello D, Pristine G, Slutsky AS: Mechanical ventilation affects local and systemic cytokines in an animal model of acute respiratory distress syndrome. Am J Respir Crit Care Med 1999, 160:109-116.

7. Ware LB, Matthay MA: The acute respiratory distress syndrome. N Engl J Med 2000, 342:1334-1349.

8. Frank JA, Matthay MA: Science review: mechanisms of ventilator-induced injury. Crit Care 2003, 7:233-241.

9. Froese $A B$ : High-frequency oscillatory ventilation for adult respiratory distress syndrome: let's get it right this time! Crit Care Med 1997, 25:906-908.

10. Hudson LD: Protective ventilation for patients with acute respiratory distress syndrome. N Engl J Med 1998, 338:385-387.

11. Marini JJ: Recruitment maneuvers to achieve an "open lung"- whether and how? Crit Care Med 2001, 29:1647-1648.

12. Slutsky AS, Drazen JM: Ventilation with small tidal volumes. N Engl J Med 2002, 347:630-631.

13. dos Santos CC, Slutsky AS: Overview of high-frequency ventilation modes, clinical rationale, and gas transport mechanisms. Respir Care Clin N Am 2001, 7:549-575.

14. Slutsky AS: Nonconventional methods of ventilation. Am Rev Respir Dis 1988, 138:175-183.

15. Imai Y, Slutsky AS: High-frequency oscillatory ventilation and ventilatorinduced lung injury. Crit Care Med 2005, 33:S129-S134.

16. Krishnan JA, Brower RG: High-frequency ventilation for acute lung injury and ARDS. Chest 2000, 118:795-807.

17. Rimensberger PC: ICU cornerstone: high frequency ventilation is here to stay. Crit Care 2003, 7:342-344.

18. Derdak S, Mehta S, Stewart TE, Smith T, Rogers M, Buchman TG, Carlin B, Lowson S, Granton J: High-frequency oscillatory ventilation for acute respiratory distress syndrome in adults: a randomized, controlled trial. Am J Respir Crit Care Med 2002, 166:801-808.

19. Bollen CW, van Well GT, Sherry T, Beale RJ, Shah S, Findlay G, Monchi M, Chiche JD, Weiler N, Uiterwaal CS, van Vught AJ: High frequency oscillatory ventilation compared with conventional mechanical ventilation in adult respiratory distress syndrome: a randomized controlled trial [ISRCTN24242669]. Crit Care 2005, 9:R430-R439.

20. Demory D, Michelet P, Arnal JM, Donati S, Forel JM, Gainnier M, Bregeon F, Papazian L: High-frequency oscillatory ventilation following prone positioning prevents a further impairment in oxygenation. Crit Care Med 2007, 35:106-111.

21. Ferguson ND, Cook DJ, Guyatt GH, Mehta S, Hand L, Austin P, Zhou Q Matte A, Walter SD, Lamontagne F, Granton JT, Arabi YM, Arroliga AC, Stewart TE, Slutsky AS, Meade MO, OSCILLATE Trial Investigators; Canadian Critical Care Trials Group: High-frequency oscillation in early acute respiratory distress syndrome. N Engl J Med 2013, 368:795-805.

22. Young D, Lamb SE, Shah S, MacKenzie I, Tunnicliffe W, Lall R, Rowan K, Cuthbertson $\mathrm{BH}$ : High-frequency oscillation for acute respiratory distress syndrome. N Engl J Med 2013, 368:806-813.

23. Fort P, Farmer C, Westerman J, Johannigman J, Beninati W, Dolan S, Derdak S: High-frequency oscillatory ventilation for adult respiratory distress syndrome-a pilot study. Crit Care Med 1997, 25:937-947

24. Ferguson ND, Chiche JD, Kacmarek RM, Hallett DC, Mehta S, Findlay GP Granton JT, Slutsky AS, Stewart TE: Combining high-frequency oscillatory ventilation and recruitment maneuvers in adults with early acute respiratory distress syndrome: the Treatment with Oscillation and an Open Lung Strategy (TOOLS) Trial pilot study. Crit Care Med 2005, 33:479-486.
25. Mehta S, Granton J, MacDonald RJ, Bowman D, Matte-Martyn A, Bachman T, Smith T, Stewart TE: High-frequency oscillatory ventilation in adults: the Toronto experience. Chest 2004, 126:518-527.

26. Adhikari NK, Bashir A, Lamontagne F, Mehta S, Ferguson ND, Zhou Q, Hand L, Czarnecka K, Cook DJ, Granton JT, Friedrich JO, Freitag A, Watpool I, Meade MO: High-frequency oscillation in adults: a utilization review. Crit Care Med 2011, 39:2631-2644

27. Wunsch $\mathrm{H}$, Mapstone J: High-frequency ventilation versus conventional ventilation for treatment of acute lung injury and acute respiratory distress syndrome. Cochrane Database Syst Rev 2004, 1:CD004085.

28. Sud S, Sud M, Friedrich JO, Meade MO, Ferguson ND, Wunsch H, Adhikari NK High frequency oscillation in patients with acute lung injury and acute respiratory distress syndrome (ARDS): systematic review and meta-analysis. BMJ 2010, 340:C2327.

29. Cochrane Handbook for Systematic Reviews of Interventions. [http://www.cochrane.org/training/cochrane-handbook]

30. Higgins JP, Thompson SG, Deeks JJ, Altman DG: Measuring inconsistency in meta-analyses. BMJ 2003, 327:557-560

31. Shah SBFG, Jackson SK, Smithies MN: Prospective study comparing HFOV versus CMV in patients with ARDS. Intensive Care Med 2004, 30:S84

32. Sud S, Sud M, Friedrich JO, Wunsch H, Meade MO, Ferguson ND, Adhikari NK: High-frequency ventilation versus conventional ventilation for treatment of acute lung injury and acute respiratory distress syndrome. Cochrane Database Syst Rev 2013, 2:CD004085.

33. Arnold JHHJ, Toro-Figuero LO, Gutierrez J: High-frequency ventilation versus conventional mechanical ventilation in pediatric respiratory failure. Crit Care Med 1995, 23:1444-1446.

34. Papazian L, Gainnier M, Marin V, Donati S, Arnal JM, Demory D, Roch A, Forel JM, Bongrand P, Bregeon F, Sainty JM: Comparison of prone positioning and high-frequency oscillatory ventilation in patients with acute respiratory distress syndrome. Crit Care Med 2005, 33:2162-2171.

35. Mentzelopoulos SDMS, Malachias S, Tzoufi M, Markaki V, Zervakis D, Pitaridis $M$, Zakynthinos S: High frequency oscillation and tracheal gas insufflation for severe acute respiratory distress syndrome. Intensive Care Med 2007, 33:S142.

36. Sedeek KA, Takeuchi M, Suchodolski K, Vargas SO, Shimaoka M, Schnitzer JJ, Kacmarek RM: Open-lung protective ventilation with pressure control ventilation, high-frequency oscillation, and intratracheal pulmonary ventilation results in similar gas exchange, hemodynamics, and lung mechanics. Anesthesiology 2003, 99:1102-1111.

37. Gattinoni L, Caironi P, Cressoni M, Chiumello D, Ranieri VM, Quintel M, Russo S, Patroniti N, Cornejo R, Bugedo G: Lung recruitment in patients with the acute respiratory distress syndrome. N Engl J Med 2006, 354:1775-1786.

doi:10.1186/cc13900

Cite this article as: Gu et al.: Is high-frequency oscillatory ventilation more effective and safer than conventional protective ventilation in adult acute respiratory distress syndrome patients? A meta-analysis of randomized controlled trials. Critical Care 2014 18:R111.

\section{Submit your next manuscript to BioMed Central and take full advantage of:}

- Convenient online submission

- Thorough peer review

- No space constraints or color figure charges

- Immediate publication on acceptance

- Inclusion in PubMed, CAS, Scopus and Google Scholar

- Research which is freely available for redistribution 